\title{
The Next Generation of Technology: Mobile Apps in the English Language Classroom
}

\author{
http://dx.doi.org/10.3991/ijet.v11i04.5293 \\ Jenny Eppard, Omaima Nasser, Preeya Reddy \\ Zayed University, United Arab Emirates
}

\begin{abstract}
The purpose of this research was to make suggestions for choosing Apps for a Foundation level English program in the United Arab Emirates. The program had to prepare for the integration of iPads into the English program for approximately 800 students. To prepare, the program launched a pilot study with a small group of teachers, administrators and technology specialists. We used qualitative research to fulfill our research needs which included participant diaries, focus groups, a research journal and observations. From the data, we developed a list of criteria for choosing Apps and a process for selecting Apps.
\end{abstract}

Index Terms-iPads, Apps, higher education; mobile learning, App review, English as a Second Language, English as a Foreign Language, Second Language Learning, education, university, UAE

\section{RATIONALE}

Starting in Fall 2012, all Academic Bridge Program (ABP) students at Zayed University (ZU) were required to have an iPad for their Foundation English classes. Previously, both teachers and students used laptops in their classes. However, that year, students switched to iPads, while teachers were given both laptops and iPads.

In order to prepare for the transition, an iPad Pilot team was organized consisting of faculty from the Academic Bridge Program. Eight teachers in total - five from ZU Dubai campus and three from ZU Abu Dhabi campus volunteered to participate in the study. Teachers split their time between teaching, and curriculum development geared toward developing materials or planning for iPad integration. The teachers' technology skills were mixed. Some were novice iPad users while others were more experienced with using the iPad as an instructional tool or with e-learning in general. The primary purpose of the pilot study was to determine possible ways to choose applications and effectively use iPads in a foundation English program in the Gulf region. It was also to determine the key characteristics of different applications as this study took place during the early stages of iPad use in education when there was a very limited amount of empirical evidence available on this subject at the time.

The adoption of the iPad as an instructional/ learning tool was expected to align with $21^{\text {st }}$ Century IT Skills [13]. These are: to use technology as a tool to research, organize, evaluate and communicate information, use digital technologies (computers, PDAs, media players, GPS, etc.), use communication/ networking tools and social networks appropriately to access, manage, integrate, evaluate and create information to successfully function in a knowledge economy, apply a fundamental understanding of the ethical/legal issues surrounding the access and use of information technologies [20]. [10] stated that using iPads creates a learning environment that is, "highly communicative, highly collaborative and self-directed", which supports the directives outlined in the $21^{\text {st }}$ Century Skills Framework.

\section{FRAMEWORK}

[23] and [19] position mobile learning within a social constructivist called Activity Theory (AT). Using AT as a lens, mobile learning would be viewed and indeed investigated holistically. Various characteristics are considered in order to better understand the phenomenon, such as the community involved, the rules, the subject, the medium (tool or artifact), the division of labor and the objective. Activity Theory has long been associated with language learning. According to Vygotsky, the notion of imitation (artifact) and collaboration is at the forefront of language learning [16]. Keeping this approach in mind, it is important to determine the types of mediums provided through mobile learning within a second language context and potential for collaboration that it affords.

\section{LITERATURE REVIEW}

\section{A. Mobile learning in the second language classroom}

While there is much research available about mobile learning in an educational setting, there are few empirical studies about its use in a language classroom. Mobile learning can be divided between before 2010 - and the introduction of the iPad into education - after 2010. Before 2010, much of the research includes Palm devices, mobile phones and other hand-held devices such as the iPod. Most of these studies can be narrowed to several topics, including the following: SMS messaging to teach vocabulary [3], [6], [21], [17], [1]; general vocabulary instruction [4], [9]; pronunciation [3]; listening skills [18]; student usage [8] and student perceptions [11], [8].

In the study conducted by [21], the authors found that students preferred instruction through mobile devices that is natural and not burdensome. This study included vocabulary instruction through SMS messages. Since SMS messages have become a normal part of life, instruction provided through a broadcast via a messaging system was perceived as efficient and seamless. In a study conducted by [11], students perceived vocabulary acquisition as a benefit to mobile learning over more traditional methodologies. Participants also stated that mobile learning improved their grammar and reading abilities. [2] established that mobile learning in the form of MP3s benefited students in oral acquisition if used over a long period (significant gains were noted after eight and twelve weeks). Students performed better in discriminating between vow- 
els and consonants, and in listening comprehension. Research conducted by [5] after the implementation of iPads in a Japanese university showed that mobile learning, specifically iPads, worked better if attention was given to App selection, task choice, teacher training and collaborative activities.

While not necessarily a second language learning context, but definitely a second culture context, [4] investigated the successfulness of incorporating mobile learning into an English literature and translation course in Iran. The author found that there were several advantages to using mobile learning for vocabulary instruction, such as: it is more effective than using flashcards, it is ubiquitous [15], [18], it provides instant feedback; information can be located instantly via the Internet and there are increased interactions between the teacher and the student and the student and the student.

On the whole, the findings for using mobile devices in language learning (or MALL) are positive. However, a study conducted by [11] warns that while mobile devices can be advantages can be advantageous in a second language classroom, instruction should be well-prepared in both resources and technology.

\section{B. App Selection}

It is difficult to determine a clear method for choosing apps. In learning environments, there are numerous different contexts and sub-contexts. In a report, [24] evaluated educational apps based on the following characteristics:

TABLE I.

VINCENT'S LIST OF CHARACTERISTICS USED TO SELECT APPS

\begin{tabular}{|l|l|}
\hline Relevance & $\begin{array}{l}\text { the app's focus has a strong connection to the } \\
\text { purpose for the app and how appropriate it is for } \\
\text { the students }\end{array}$ \\
\hline Customization & $\begin{array}{l}\text { the app offers complete flexibility to alter content } \\
\text { and settings to meet student needs }\end{array}$ \\
\hline Feedback & the student is provided specific feedback \\
\hline Thinking Skills & $\begin{array}{l}\text { the app encourages the use of higher order think- } \\
\text { ing skills including creating, evaluating and } \\
\text { analyzing }\end{array}$ \\
\hline Engagement & the student is highly motivated to use the app \\
\hline Sharing & $\begin{array}{l}\text { sharing specific performance summary or student } \\
\text { product is saved in the app and can be exported to } \\
\text { the teacher or for an audience (para. 4) }\end{array}$ \\
\hline
\end{tabular}

[7] suggests getting free apps instead of paid apps. He also recommends that programs create their own digital textbooks with apps such as iBook author [7].

While [24] and [7] provide suggestions for choosing apps based on certain characteristics, [12] recommends considering the process shown in Table II for choosing them.

A newer study by [22] states that there is a need to align apps to curriculum standards, focal points and norm referenced tests. She identifies seven steps to help teachers focus their efforts in order to successfully select apps with targeted content and specific learning outcomes. The steps are as follows:

- Step 1: Identify Learning Objectives

- Step 2: Select Targeted Apps

- Step 3: Select Standards to align with the App
TABLE II.

THE Process OF CHOOSING APPS ACCORDING TO GLICKSMAN (2011)

\begin{tabular}{|l|l|}
\hline 1 & $\begin{array}{l}\text { Have you explored and identified different applications that } \\
\text { teachers want to use? }\end{array}$ \\
\hline 2 & $\begin{array}{l}\text { Have you tested these applications and ensured they meet } \\
\text { required standards and comply with your educational objec- } \\
\text { tives? }\end{array}$ \\
\hline 3 & $\begin{array}{l}\text { Are there existing projects that require teachers and students } \\
\text { use specific applications? If so, will they be able to use them } \\
\text { on the iPads? Has this been tested? Some desktop applications } \\
\text { will not work on the iPad or may work very differently. }\end{array}$ \\
\hline 4 & $\begin{array}{l}\text { Are you using applications that require flash? Some examples } \\
\text { include popular websites such as VoiceThread and Glogster. } \\
\text { Flash based sites will not currently work on the iPad. }\end{array}$ \\
\hline 5 & $\begin{array}{l}\text { Have you decided on a set of core apps for important functions } \\
\text { such as note taking, document distribution, book reading and } \\
\text { more? (para. "application Usage") }\end{array}$ \\
\hline
\end{tabular}

- Step 4: Identify limitations and essential features

- Step 5: Choose an App

- Step 6: Identify Unique Learning Needs of Students with Disabilities

- Step 7: iPad Setup

Although these steps may be time-consuming, the process allows teachers to gather data to justify students' use of particular apps. Some of her suggestions repeated those purported by [12] or are not relevant to the learning situation at Zayed University.

Many of the recommendations provided by [22], [12], [7] and [24] were referred to at various times throughout this study. However, question 3 provided by [12] was not included. We believe that this might be partly due to the context of our program and its level of iPad integration at the time of the study. Specific projects that integrated the iPad did not appear in a systemic manner until later on in the form of an integrated skills project. Also, we stayed away from any app or website that needed Flash. We did, however, use browsers that were able to use Flash, but we found the loading time to be especially slow. While these lists are useful, we felt that the research available on how to choose apps for our particular needs was limited. We will mention these, as we discovered through data collection and analysis, that a combination of these points was useful for choosing future apps.

The purpose of this qualitative study at the time was to decide which iPad apps worked best with the current curriculum at Zayed University's Academic Bridge Program (ABP). The Academic Bridge Program is an English Foundation program that aims at improving students' English academic proficiency before starting studies toward their majors. Therefore, we wanted to provide a list of apps that we felt best supported the program's aims and objectives and to determine a strategy for evaluating future apps based on the specific needs of the ABP program and its students. In order to reach these goals, we explored the following research questions:

1. Which apps supported the curriculum in the ABP at Zayed University?

2. How could the ABP community at Zayed University best evaluate iPad apps for its particular needs?

The aim of this paper is to explain the process that our program underwent in choosing relevant apps before the 
full implementation of iPads into the program, in the Fall of 2012. While much of the information provided in this study is specific to our institution, many of the steps involved could be replicated elsewhere.

\section{THE STUDY}

The setting was the Academic Bridge Program (ABP) at Zayed University in the UAE. The teachers involved in the study used the iPad in seven classes. There were four classes in Dubai and three in Abu Dhabi. The total number of students was 76 and the levels were diverse. Teachers taught the following sections: 010 (the beginning level), 020, level 6, level 7 (intermediate and upper-intermediate levels) and level 8. Levels were not specifically selected for the study. Instead, teachers were allocated classes based on normal procedure at the university. That meant that teachers chose the levels that they wanted to teach and were given their preference when possible. Management did not interfere with the teacher's preference by asking them to choose specific levels.

Participants included seven teachers, three administrators and two staff members from the Computer Science Department at ZU. There was a range of technology literacy in the group. Some of the teachers were comfortable with technology while others had limited knowledge. The teachers were chosen because they volunteered to participate in the group; though management did try to make sure that there was a spectrum of technological abilities within the group. The volunteers came from various national backgrounds: the United States, the United Kingdom, Australia and New Zealand since this is typical of the faculty and staff employed at ZU.

\section{A. Process}

This research was exploratory as using the iPad within an educational context was still relatively new territory at the time. In order to better understand the phenomenon, we collected data through focus groups and diaries. In addition, participants also agreed to data collection through relevant conversations and e-mails.

\section{B. Instruments}

In order to create a pool of apps for teachers to use in the class, we read several blogs dedicated to recommending apps for education, and specifically for language classes and/or higher education. This step naturally followed Glicksman's (2011) first step which refers to researching relevant apps. From these sites, we made a list of apps (in a table) that we could use during the pilot study. The table included the following topics: App name, image, description, link, cost, skill and a column for Yes or No. During the course of the study, teachers found other apps that they wanted to try in the study, so the list was not exhaustive. Since the use of iPads in the classroom was not well established at the time, we wanted teachers to try apps that fitted within the curriculum and their own classroom practices.

The participants completed a diary as well. Prompt questions were accessible although not all of the questions were applicable on a daily basis. These were semistructured so other questions could emerge throughout the study. In addition, participants were free to add any information that they deemed relevant. Teachers used the diaries to keep track of experiences and to express any concerns. In addition to the diary, there were semistructured questions that were used during focus groups.

We, as the principle investigators in this study, were instruments as well as researchers. We were teachers in the ABP during this time, but we did not participate as subjects in the pilot. We took field notes during the focus groups, when reading the diaries and when discussing the pilot study with the participants.

\section{Data Collection}

As mentioned before, participants kept diaries about their experiences that included prompt questions with using the iPad in their classes. Some of the questions were not answered every day. Consequently, teachers were only encouraged to answer questions when they were relevant. Diaries were kept in a digital format using a locked-down Googledoc file.

Focus groups took place every two weeks due to time constraints of the members of the teams. The questions were semi-structured, though other questions arose during the sessions, too. In addition, at times, information was gathered during informal meetings and emails but only when the information was relevant

\section{RESULTS}

Even though the groups were free to explore any apps that suited their particular purpose, surprisingly most seemed to try the same apps. In the end, the group reviewed and tried the numerous apps. According to the list of questions provided by [12], this follows his question recommending that apps be tested before full implementation. Although Apple has numerous labels for the apps available in the app store, the types of apps that participants tried during this study were limited to the following: productivity, news, education, entertainment, photos and videos, utilities, references, business and books. The productivity apps used by teachers in this project were found to be the most versatile for this particular group of participants because they are used to organize, make notes, annotate, organize and share documents as well as download items from various sources.

According to the data collected, apps needed to have the following features: the ability to share, the ability to collaborate, to customize, to keep students engaged, to address thinking skills and to provide feedback. All of these are the characteristics highlighted by [24]. In addition to these items, data from this study highlighted the need for culturally relevant apps and those that were easy to use. In accordance with [7], the participants discussed apps in terms of cost as well, regarding the free ones as a benefit.

Sharing. The ability to share was one of the more important functions mentioned by the participants and when the app would not permit sharing easily, teachers would become frustrated. One teacher highlighted the benefit of syncing and sharing information across devices. When using Evernote, this participant stated that users could: "open word files from Blackboard. If students use this method, they have the document across ALL of their devices" (online data n.d.). Part of sharing in this study included the ability to access, upload and download items. Teachers claimed that when sharing was easy and flexibility was present, the students enjoyed using the iPad: "Today, I used GoodReader. The students found it very easy to download documents, to mark them up and also to save 
them inside the app. It was a good experience for them. They remember how to use it from a couple of days ago." (online data April 25).

When students or participants could not access or download items, teachers would become discouraged since the experience disrupted the classroom flow: "students could not access listening files" (online data April 22) and "links uploaded on the laptop are not always seen on the app." The same was true when students had difficulties downloading items: "students can not download word documents into the Pages app" (online data May 1) or "users cannot download a pdf version of the textbook and the clickable textbook does not work correctly" (online data May 3). Teachers wanted students to be able to send work through email and if this function was not available or easily accessed, they complained about it in their diaries:

Educreations is a fairly easy app to use and the majority of students were able to easily record their voice over the presentation then email the finished product to me. There were three students however who for whatever reason couldn't set up an account so were unable to send it to me. I tried to create a new account for them but after numerous attempts I gave up and just marked their presentations on their iPads (online data June 3).

Over time, many of these issues were fixed but these comments indicate the need for reliable sharing including uploading and downloading materials.

Collaboration. The ability to collaborate was seen as a positive trait and teachers mentioned how they wanted an effective app that students could use like Googledocs:

we tried to contribute and collaborate on one Mindmeister brainstorm. This was a disaster. You can't have 15 students all trying to edit and save one copy of the brainstorm. People's work was being deleted or not even saving. I then tried to get students to just use one iPad per group of 3 but even this was problematic. In my opinion, Mindmeister isn't great for synchronous collaboration across multiple iPads. It could work great asynchronous$l y$, individually or even $f-2-f$ collaboration and one person uploads to iPad (online data Week 7).

As mentioned earlier, some of these issues have been resolved since, but it is an important function that app developers may want to consider when designing for educational contexts.

Customization. Teachers also commented on the benefits of students' ability to customize information in the apps such as in GoodReader (GR): "Students were able to annotate and save PDFs in GoodReader. "Today, they created folders for their grammar and writing worksheets. After they finished their work today asked them to email it to me which they were able to do easily." (online data April 26). The ability for students to access special functions that were not easily obtained at the time was also considered desirable: "decided to have students download the GoodReader app to use instead of or in conjunction with Goodnotes. The GR app is only $\$ 4.99$ but it allows Blackboard users the ability to download and open a zipped file in the app. This may be particularly useful for anyone who has zipped files in their Blackboard course". (online data n.d.). When teachers could not customize apps, then the class had some issues:

Today we used "Brainpop" in the class and I have to say that it didn't work as well as I'd hoped. It is far above the level of 010; even the language/grammar sections. I could see how it would be useful for higher levels, especially as they deal with content from the course. This app could end up being useful for the Content courses currently being developed for the higher levels (online data April 30).

It may be preferable for teachers to have the option to adjust levels or have access to similar apps at a lower level.

Engagement. In accordance with [24], engagement created a positive experience for app use. This teacher used the Brainpop app with students:

I got students to download this app and use it to do listening work using listenings about dyslexia and ADHD. Students did a split listening and note taking and produced peer questions based on their notes. Students swapped questions and then listened to the other listening. Students were focused and enjoyed using the app. The app work well and is a useful tool to practice listening related activities. Students do need to have headphones with them (online data week 2).

Another teacher claimed that using the drawing app Skitch engaged students:

Whilst not all used English all the time, I did see a lot of people enthusiastically drawing and then presenting with smiles. I think they knew their audience was expanding and not just me, so they wanted their picture to be decent. Most quite eagerly talked about their drawing and did hear some on-topic vocab. Here student creation was on display to me and I like what I see. I've always tried to ask students to create but the added dimension of drawing and interaction with iPad helps a lot (online data May 8).

According to the teachers in these comments, engagement helped with focus and motivation.

Thinking Skills. Thinking skills are generally difficult to measure, but here teachers mentioned students using the iPad to create maps to help organize their thoughts: "the app is good for brainstorming, organizing and sequencing" (focus group June 12). Another teacher, asked students to complete an activity that included several different actions:

Had a very nice day with the iPad today. We used the app "educreations". After a short introduction to the app, we went to the library LEC listening room and I had the students listen to a book on CD. While they were listening, I had the draw pictures of what they heard on educreations. It seemed as though it really focused their listening and acted as a pre-cursor to note-taking. It was very successful. If I were to do it again, I would probably do it as a whole class listening exercise so that the students could compare their drawings with each other (online data Apil 29).

Still another teacher discussed a possible use for an app that could be used for a scavenger hunt or other activities:

We also used the app "Aurasma Lite" today and I had the students record videos of various locations in the classroom. This app would be great for something like a scavenger hunt or orientation, provided the "channels" don't get too overloaded. I'm sure there are teachers who would find other more creative ways to use it (online data May 6).

All of these comments include either creating or evaluating information needed to complete a task. 
Relevance. Teachers commented on using apps that were relevant to teaching English content to students. They wanted to use apps that would increase their students' exposure to reading: "Students are starting to read articles on FlipBoard now" (online data Week 6). Even though there were some issues with the app and its ease of use, teachers thought that students benefited by reading articles on them. Teachers also used apps for other English skills such as listening: "students watched a video and took a quiz, no problems...gives authentic listening input and assesses it with its own quizzes" (online data April 26); and grammar: "We have been using Socrative every day in class for daily grammar quizzes which works really nicely" (online data May 3), "this contains three forms of verbs - infinitive - past simple - past participle. While it does not offer any exercises, it might be useful as a reference tool and is easy to access" (online data Week 6).

Feedback. While feedback was not mentioned often, participating teachers suggested it was a beneficial characteristic in an app: "Instant feedback, there are quizzes and games, students are accountable, students can see what they are doing at the same time" (focus group June 12). Teacher feedback could also be given through apps like Notability and sent to the students through email, or other data sharing apps.

Multiple features. Some apps such as Notablity included many of the features as outlined by [24]. This app could be relevant for tasks like reading and note-taking; work could be shared, uploaded or downloaded; and functions such as script type and color could be customized:

The main strength of Notability is that you can input information though handwriting, typing, recording within the document and uploading photos and video recordings. This means a document can contain a variety of data compiled about a particular topic etc... In particular I believe it can be an effective revision tool where students can store key information about a topic, text etc... in one place. To this end I used it in class to encourage students to record information about topics that would be covered in the LDA speaking exam. The other strength of this app is that students can then share the document easily with other students or their teacher. Also unlike documents created in Pages documents produced in Notability can be directly saved to Drop Box. At a cost of 99 cents it is certainly worth students buying or gifting it to them. I wish I had tried it out earlier so that I could have explored it uses more (online data Week 6).

Students could also upload pictures, crop and save documents in several formats. Due to its flexibility, Notability was reviewed highly by the team. According to the teachers, the App was cheap and worth the university's investment.

Cost. In accordance with [7], teachers mentioned the benefit of free apps:

I have been using Edmodo to set up my class site this term. They have a free app which works really nice on the iPad. It is really easy to set up and students seem to navigate their way around very easily. Features I like include:

1. Shared library - a great way to share documents and organize documents with students

2. Syncs with google docs

3. Students can turn in assignments through Edmodo.

4. Students can easily send you a message
5. You can easily embed objects and you can upload photos from your camera roll on your iPad (online data May 3).

This particular app was free, but users were also able to share and customize information using the app. The point is that even free Apps need to enhance the learners' experience in some capacity.

Training. Apart from the characteristics and steps recommended by [7], [12], [24] and [22], teachers suggested several other items to be considered when choosing apps, as part of an iPad integration process. For example, they recommended that teachers be trained on the use of apps that may have a learning curve:

I think teachers are going to want to know how Blackboard works with the iPad right away because they will want to see what items from their normal course will work and what won't work and how to work around or adjust those things that won't work. For example: How will I change an audio file that is in Blackboard so that it will play directly on the iPad? (online data n.d.)

They also recommend that students may need some training as well: "need some training" (online data May 16) for GoodReader.

User-friendly and Maintained properly. Often training and/or incorporation could depend on how user-friendly the app was:

It took them a while to get the hang of it. The trouble with Flipboard, and upon reflection this could be true for many apps, is that the app never wants you to leave and forces the user into different windows or sections within sections of the app. Flipboard starts easy but then when you start clicking through and reading articles, it got a little confusing for some students. Some thought they were in Safari and others said they couldn't go back to the main screen. These are navigation and app environment awareness issues (online data Week 6).

Another teacher wrote the following about an app: "the app thus far has been a failure. Even I had trouble getting my head wrapped around the functionality of it but students have had a tougher time so far" (online data April 24). Ease of use included the students' ability to sync apps: "getting all of the students Dropbox accounts set up and syncing with their iPads was a little problematic without having their laptops in the classroom. It's also fairly confusing to them." (online data, May 28-June 11).

Often, though, participants used the apps easily and without issue: "Taught students how to save in class whiteboard notes into Evernote for later reference. They seemed to like that one a lot. It involves very little effort and can be easily referenced later with the proper tags (which I also showed them) (online data April 21); teaching them how to use it took only about 2 or 3 minutes. They really enjoyed the user interface" (online data May 20); "there are quite a number of options they can choose so this would take practice over time. However, it is relatively easy for students to pick up" (online data May 22); "Students used iMovie to produce films of the field trip we took to the Dubai Mall. They were successful at using the camera/video functions on their iPads at the mall, with very little instruction, and were subsequently able to produce the iMovie videos, also with little instruction". (online data May 28-June 11). Teachers recognized, though, that in order for apps to be successful, the app 
developers needed to monitor and update the apps when there was an issue:

Also in the last two days I have managed to get students orientated to using the VoiceThread app which seems to at last be functioning okay. What I noticed with the practice task I did is that students are not so comfortable recording their voice and prefer to use the writing function for comments. This may just be that they are not used to recording themselves or are shy. I had a similar experience using Keynote last week (online data May 6).

Teacher's Recommendations. During a focus group, a few teachers reflected on the factors that should go into selecting apps and using the iPad in the classroom, such as:

- time spent on this activity,

- the value I place on this for language learning

- the curriculum objectives being met

- the value and motivation students get from this

- effect on students' language learning (online data Week 1)

- free or cheap

- simple and easy to use (online data Week 5)

Two teachers commented on the types of apps that they would like to see in the future: better collaborative writing apps, like Googledocs. Something more flexible than SyncSpace; content-based apps that are ESL/EFL focused; ones that provide a reading resource for students; a kind of library resource.

\section{DISCUSSION}

In reference to Vincent's (2012) criteria: (1) relevance; (2) customization; (3) feedback; (4) thinking skills; (5) engagement; and (6) sharing, some of the detailed description of the participants" experiences with the apps explored in this study, support these criteria. In addition to this list, Coxon's (2012) suggestion that cost factors into the apps chosen seemed to be a valid recommendation based on participants' comments. For example, Notability was one of the apps that fit the sharing criteria; teachers indicated that they wanted apps that enabled students to collaborate in real time similar to Googledocs. They also mentioned that they wanted relevant content-based apps. Moreover, engagement was used to describe the entire experience and not one particular app. Furthermore, cost as well as ease of use, was cited as a factor to consider when choosing future apps. Based on this information, this study also added to Vincent's (2012) and Coxon's (2012) suggestions, in recommending that apps should be user-friendly (for at least some educational environments), collaborative, updated and monitored. In addition to these features, we believed that training be a crucial step in app adoption. Administrative decisions regarding which apps to offer the students were based on recommendations made in this study. As a result, the ABP purchased eight paid apps for each student and teachers that year in addition to downloading eleven free apps. Naturally, the cost of buying apps for some institutions or students may not always be feasible. Therefore, we agree with [7] and recommend exporting the best free apps that fit into the context of the different institutions. The following is a list of recommended features of Apps as suggested in this study and supported by [24] and [7]:

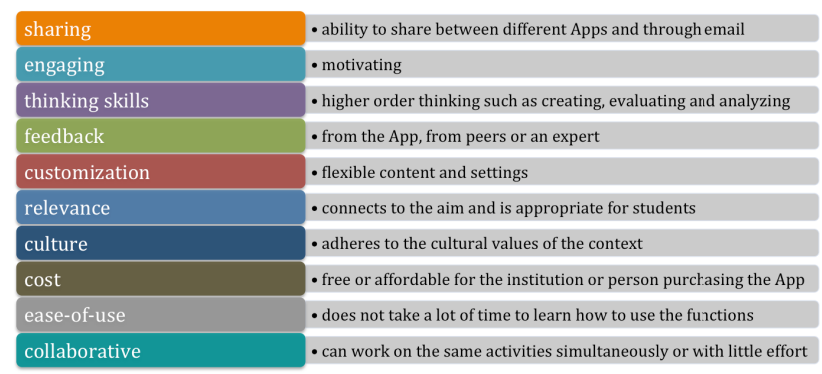

Figure 1. Features of Apps based on Vincent (2012) and Coxon's (2012) work and the findings from this study

It is important to note that this was an exploratory study meant to be the first in a line of ensuing research and projects. It is almost impossible for teachers to know everything about the iPad, how to fully implement it in the classroom and investigate all of the potential apps available. This study, nonetheless, is useful in that it provides an idea of how the iPad can be used and should be viewed as a foundation from which to research it in the future. In general, the participating teachers believed that the iPad would work well in the ABP. One teacher provided an example of how enthusiastically the students used the iPad as a learning tool:

Students were in groups, sharing their iPads, they would simply give their screen to others to show them, they would zoom in and out on each others screens, they were all searching and viewing design and writing English words to help them...(online data April 29, 2012).

Through their diaries, the teachers provided numerous examples of how the iPad could be used as a classroom tool. They explained any issues that occurred and explored possible solutions. Based on this study, therefore, we recommend the following process for choosing apps:

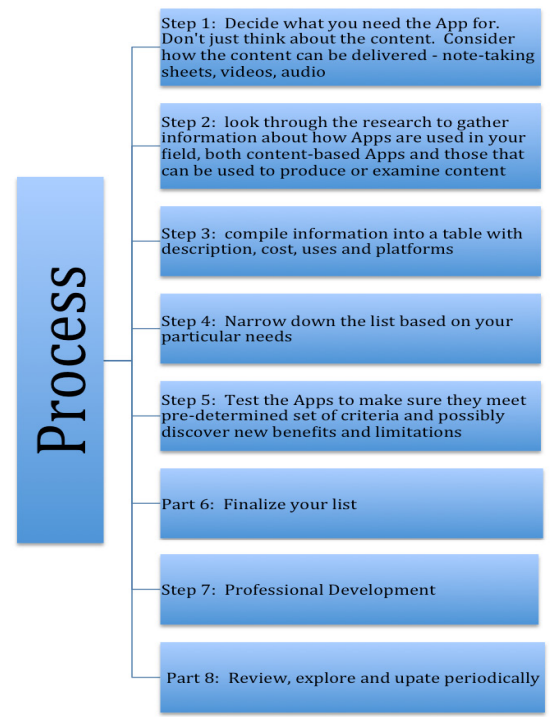

Figure 2. The process of choosing Apps based on the work of Glicksman (2011) and Powell (2014) with additions from this study

The findings of this study coincide with the analysis of [19] and [23] which highlight the collaborative significance of mobile learning and indeed language learning. This is also extended to the affordances provided through mobile learning which allow student to imitate, as needed from any location, skills provided through the mobile medium. 


\section{LIMITATIONS}

Data was open to the group. The subjects had access to each other's diaries and comments made during meetings. Therefore, the information provided may have been influenced by the comments made by other participants. Also, some subjects may not have wanted to express their lack of knowledge in a place where peers could freely read their comments and as a result they may not have written about experiences that could potentially cause embarrassment. Therefore, valuable data may not have been included in the study. In spite of this, due to the nature of the research, collaboration was essential when problem solving and choosing apps for the program. This was not a solitary endeavor. Therefore, while everyone in the group was privy to all information, it was a necessary limitation.

Another limitation was that iPad apps are created frequently so it was impossible to keep up with all of the apps available for educational purposes. Therefore, the project was not able to look at all possible apps relevant for the ABP. Rather, its goal was to create a list of core apps that the program needed or should have in order for the iPad to be successful with the students and teachers in the ABP. In addition, at the time of the research, there were not any peer-reviewed articles about how to choose Apps for educational purposes for tablet devices; therefore, we had to review websites that individuals made to host such suggestions and apply them to our context. This research will hopefully work toward filling that gap.

\section{FUTURE RESEARCH}

In order to support the findings in this study, it would be advantageous for researchers in other contexts to replicate a similar project or use the findings to design a mixed method or quantitative study. This study was set in a specific context and iPads were the only devices used in the study. Studies conducted outside of a language learning environment would be beneficial as well as studies using various devices. After conducting numerous studies, it would be beneficial to create a rubric that is substantiated by the research and is general for various contexts and/or specific content areas.

\section{REFERENCES}

[1] Alemi, M., Sarab, M. R. A., \& Lari, Z. (2012). Successful learning of academic word list via MALL: Mobile assisted language learning. International Education Studies, 5(6), p99. DOI: http://dx.doi.org/10.5539/ies.v5n6p99

[2] Al-Jarf, R. (2012). Chapter Six Mobile Technology and Student Autonomy in Oral Skill Acquisition. Left to my own Devices: Learner Autonomy and Mobile-Assisted Language Learning, 6, 105.

[3] Anaraki, F. B. (2009, January). A flash-based mobile learning system for learning English as second language. In Computer Engineering and Technology, 2009. ICCET'09. International Conference on (Vol. 1, pp. 400-404). IEEE. http://dx.doi.org/10.1109/ICCET.2009.183

[4] Azabdaftari, B., \& Mozaheb, M. (2012). Comparing vocabulary learning of EFL learners by using two different strategies: mobile learning vs. flashcards. The EUROCALL Review, 20(2), 47-59.

[5] Brown, M., Castellano, J., Hughes, E., \& Worth, A. (2012). Integration of iPads into a Japanese university English language curriculum. The JALT Call Journal, 8(3), 193-205.

[6] Cavus, N., \& Ibrahim, D. (2009). m-Learning: An experiment in using SMS to support learning new English language words. British journal of educational technology, 40(1), 78-91. http://dx.doi.org/10.1111/j.1467-8535.2007.00801.x
[7] Coxon, D. (2012, February 26). Getting ready for iPad deployment: 10 things I'd wished I'd known about last year. [Web log comment]. Retrieved from http://darrencoxon.net/2012/02/26/ getting-ready-for-iPad-deployment-ten-things-id-wish-id-knownabout-last-year/

[8] Dang, T. H. (2013). Towards the Use of Mobile Phones for Learning English as a Foreign Language: Hesitation or Welcome? Language in India, 13(10).

[9] Fraga, L. M., Harmon, J. M., Wood, K. D., \& Buckelew-Martin, E. (2011). Digital word walls and vocabulary learning: The use of iPods to facilitate vocabulary instruction with ESL students. Journal of the Research Center for Educational Technology, 7(2), 3857.

[10] Harm, N. (2011). Transforming Classroom Practice with iPad Content Integration. Webinar given at the Reform Symposium in 2011. Retrieved from http://www.squidoo.com/free-esl-apps.

[11] Hu, B. (2012). The Challenges of Blended Learning: Critically Evaluating the Chinese Language Case. European Association for Computer Assisted Language Learning, 80.

[12] Glicksman, S. (2011, February 24). Preparing Your School for an iPad Implementation Plan [Web log comment]. Retrieved from http://iPadeducators.ning.com/profiles/blogs/preparing-yourschool-for-an

[13] Higher Colleges of Technology, United Arab Emirates University, \& Zayed University. (2012). iPad implementation framework. (No. Version 1.67). UAE Government Report.

[14] Joseph, S. R., \& Uther, M. (2009). Mobile devices for language learning: Multimedia approaches. Research \& Practice in Technology Enhanced Learning, 4 (1). http://dx.doi.org/10.1142/ S179320680900060X

[15] Kukulska-Hulme, A. (2009). Will mobile learning change language learning?. ReCALL, 21(02), 157-165. DOI: http://dx.doi.org/10.1017/S0958344009000202

[16] Lantolf, J. P. (2000). Sociocultural theory and second language learning. Oxford University Press.

[17] Lu, M. (2008). Effectiveness of vocabulary learning via mobile phone. Journal of computer assisted learning, 24(6), 515-525. http://dx.doi.org/10.1111/j.1365-2729.2008.00289.x

[18] Nah, K. C., White, P., \& Sussex, R. (2008). The potential of using a mobile phone to access the Internet for learning EFL listening skills within a Korean context. ReCALL, 20(03), 331-347. DOI: http://dx.doi.org/10.1017/S0958344008000633

[19] Park, Y. (2011). A pedagogical framework for mobile learning: Categorizing educational applications of mobile technologies into four types. The International Review of Research in Open and Distributed Learning, 12(2), 78-102.

[20] Partnership for $21^{\text {st }}$ Century Skills (2011). Overview: ICT Literacy. Retrieved from http://www.p21.org/overview/skillsframework $/ 350$.

[21] Plana, M. G. C., Torrano, P. G., \& Grova, M. E. (2012). SMS as a learning tool: an experimental study. European Association for Computer Assisted Language Learning, 33.

[22] Powell, S. (2014). Choosing iPad apps with a purpose: Aligning skills and standards. Teaching Exceptional Children, 47(1), 20-26. Retrieved from http://search.proquest.com/docview/1560258319? accountid=15192 http://dx.doi.org/10.1177/0040059914542765

[23] Sharples, M., Taylor, J., \& Vavoula, G. (2010). A theory of learning for the mobile age. In Medienbildung in neuen Kulturräumen (pp. 87-99). VS Verlag für Sozialwissenschaften. DOI: 10.1007/978-3-531-92133-4_6 http://dx.doi.org/10.1007/978-3531-92133-4_6

[24] Vincent, T. (2012, March 4). Ways to Evaluate Educational Apps. [Web log comment]. Retrieved from http://learninginhand.com/ blog/ways-to-evaluate-educational-apps.html

\section{AUTHORS}

Jenny Eppard, Omaima Nasser, and Preeya Reddy are with Zayed University, United Arab Emirates.

Submitted 18 November 2015. Published as resubmitted by the authors 26 January 2016. 